\title{
PEMIKIRAN FIQH LESTARI DAN \\ PEMAKAIANNYA KE ATAS ISU-ISU TERPILIH \\ DALAM HAL EHWAL MU'ALLAF DI MALAYSIA
}

SUSTAINABLE FIQH THOUGHT AND ITS APPLICATION

ON SELECTED ISSUES IN MU'ALLAF AFFAIR IN

MALAYSIA

\section{Atikullah Hj Abdullah}

Pusat Pengajian Ilmu Kemanusian. Universiti Sains

Malaysia. 11800. Pulau Pinang Malaysia.

Emel: atik@usm.edu.my

\section{Khulasah}

Adalah sangat penting untuk memastikan fiqh Islam sentiasa hidup, dinamik dan releven dengan masalah, realiti dan latar semasa dan setempat masyarakat. Ini membolehkan fiqh Islam sentiasa lestari dan berada dalam arus perdana kehidupan masyarakat Islam. Untuk mencapai matlamat ini, beberapa ciri kelestarian fiqh Islam yang sedia ada seperti yang ditunjukkan oleh para fuqaha' silam perlu ditonjolkan dan diberikan kedudukan utama. Fiqh dengan ciri-ciri kelestarian atau fiqh lestari inilah yang seharusnya dijadikan panduan dalam menilai isu-isu semasa yang berkaitan. Antara isu semasa yang perlu dilihat dari perspektif fiqh Islam yang lestari ialah yang berkaitan hal ehwal mu'allaf. Banyak isu yang berkaitan hal ehwal mu'allaf perlu ditangani secara bijaksana dan lestari supaya maslahah semua pihak dapat dipelihara sebaiknya dan fiqh Islam sentiasa diyakini.

Kata kunci: Fiqh lestari, pemikiran fiqh, mu'allaf, hal ehwal mu'allaf, fiqh mu'allaf.

\footnotetext{
Abstract

It is very crucial to ensure that Islamic fiqh continues to be dynamic and relevant to the realities of the contemporary societies. This will result in the sustainabilty of fiqh and make it acceptable within
} 
the societies main stream. Towards this end, all the existing qualities of fiqh as shown to us by the fiqhi scholars in the past need to be highlighted and brought forward. The fiqh with the sustainability qualities or sustainable fiqh as mentioned above need to be put into practice as the guide line in evaluating some related contemporary issues. In mu'allaf affair for example, there are issues need to be adressed properly and wisely using sustainable fiqh principles to ensure the interest of all are well protected and the Islamic fiqh is always trusted.

Keywords: Sustainable fiqh, fiqh thought, mu'allaf, mu'allaf affair, mu'allaf fiqh.

\section{Pendahuluan}

Secara kasarnya artikel ini bertujuan untuk membincangkan tentang bagaimana seharusnya beberapa isu yang berkaitan mu'allaf dilihat dari perspektif fiqh lestari. Untuk tujuan itu, maka pada permulaannya artikel ini akan menghuraikan terlebih dahulu fiqh lestari sebagai satu konsep fiqh yang berteraskan prinsip-prinsip yang telah sedia ada hasil kefahaman dari sumber-sumbernya seperti yang telah ditunjukkan oleh para fuqaha' awalan dahulu. Berteraskan kepada konsep dan prinsip-prinsip yang digariskan tersebut, maka beberapa isu yang berkaitan mu'allaf dipilih untuk dibincangkan bagi memahami bagaimana ia saharusnya dilihat dan difahami secara yang lebih lestari.

\section{Konsep Fiqh Lestari}

Fiqh pada asalnya merujuk kepada pengetahuan seseorang tentang hak baginya dan kewajipan keatasnya. Takrif ini mencakupi semua bidang ilmu akidah, akhlak dan amaliyyah. Ini adalah takrif fiqh bagi Abu Hanifah kerana pada zamannya ilmu fiqh itu belum lagi dipisahkan dari ilmu lain seperti yang wujud pada hari ini. ${ }^{1}$ Bagaimanapun

\footnotetext{
${ }^{1}$ Wahbah al-Zuhayli, al-Fiqh al-Islāmīyy, jil.1 (Dimasyq: Dār al-Fikr, 1989), 16.
} 
kemudiannya fiqh dikhususkan sebagai merujuk kepada kefahaman dan pengetahuan tentang hukum hakam syariah yang praktikal berdasarkan dalil-dalil yang terperinci. ${ }^{2}$ Secara ringkasnya ia bermaksud kefahaman manusia terhadap kehendak Allah berdasarkan nas-nas yang diturunkannya.

Dalam artikel ini, pada kebanyakannya, istilah fiqh digunakan bagi merujuk kepada makna yang masyhur hari ini. Bagaimanapun, pada beberapa tempat, ia juga digunakan dalam bentuk yang umum seperti mana maknanya pada zaman awal.

Lestari mengikut Kamus Dewan bermaksud tidak berubah-ubah, kekal dan tetap. Ungkapan melestarikan sesuatu bererti menetapkan dan mengekalkan sesuatu manakala kelestarian bererti keadaan yang tidak berubah atau terpelihara seperti asal dan ungkapan pelestarian bererti perlindungan daripada kemusnahan. ${ }^{3}$

Dengan itu fiqh lestari merujuk kepada fiqh dan kefahaman terhadap nas-nas syarak dan lain-lain asas penentuan hukum yang sentiasa kekal terpelihara seperti asalnya dan pada masa yang sama sesuai dengan dinamika kehidupan masyarakat sepanjang zaman dalam lingkungan panduan dan sempadan yang digariskan oleh prinsipprinsip yang diiktiraf oleh syariat Islam. Dalam konsep ini apa yang perlu dikekalkan keasliannya ialah dari segi sumber dan prinsip-prinsipnya yang tegar dan rigid, iaitu hukum hakam yang diistinbatkan secara langsung dari nas-nas yang bersifat thabat, muhkamāt dan qat'iyyāt sama ada dari segi dalalah maupun dari segi thubütiyyah.

Manakala furu' atau pecahannya yang merupakan hukum hakam ijtihādìyy sentiasa anjal dan dinamik sesuai

${ }^{2}$ Wahbah al-Zuhayli, al-Fiqh al-Islāmīyy, 16; Musțafā al-Khīn et.al., al-Fiqh al-Manhajīyy, jil.1 (Dimasyq: Dār al-Qalam, 2003),7-8; 'Abd al-Karīm, Zaydān, al-Madkhal (Beirut: Mu'assasah al-Risalah, 1986), 62-63.

${ }^{3}$ Kamus Dewan, Edisi Keempat (Kuala Lumpur: Dewan Bahasa dan Pustaka, 2005), 932. 
dengan keanjalan dan kedinamikan kehidupan manusia. Kesesuaian fiqh dan kedudukannya sebagai panduan dan rujukan manusia dalam sebarang aktiviti kehidupan mereka akan terus berkekalan dan lestari. Penerimaan dan pengiktirafan yang berterusan terhadap ilmu fiqh sebagai panduan dan rujukan dalam menentukan nilai dan hukum setiap aktiviti fizikal manusia dalam pelbagai bidang hidup inilah yang dimaksudkan dengan konsep fiqh lestari dalam perbahasan ini.

Berdasarkan huraian di atas, melestarikan fiqh Islam antara lainnya bermaksud memastikan kedudukan dan peranan fiqh Islam agar sentiasa menjadi tunjang, pemandu dan tempat rujuk manusia sepanjang zaman seperti mana ia pernah menjadi rujukan manusia sebelum ini. Untuk itu maka dalam proses perkembangannya, fiqh Islam mestilah dipastikan agar terus berdiri kukuh di atas prinsip-prinsipnya yang mampu menjamin kelestariannya sepanjang zaman.

Kefahaman ini dirasakan sangat penting memandangkan masyarakat Islam hari ini semakin jauh atau sekurang-kurangnya tidak lagi mengambil berat atau tidak menjadikan fiqh sebagai pemandu dalam aktiviti kehidupan. ${ }^{4}$ Puncanya mungkin kerana ketidakyakinan masyarakat Islam sendiri terhadap keupayaan fiqh dan para fuqaha' semasa dalam memahami dan menjawab persoalan-persoalan moden yang semakin rumit dan komplikated. Dengan itu masyarakat lebih bergantung kepada asas-asas lain dalam menentukan dan membentuk sistem nilai dan ketentuan hukum dalam pelbagai aktiviti seharian mereka.

Situasi ini menjadikan pemahaman dan penghayatan prinsip-prinsip asas pembinaan fiqh ini sangat mustahak

4 Lihat umpamanya Yūsuf al-Qarāḍāwī, Bay ‘ al-Murābahah (alQāhirah: Maktabah Wahbah, 1995), 22, lihat juga kitab beliau Taysìr al-Fiqh, (Maktabah Wahbah, al-Qahirah, 2004), 12. Lihat juga 'Ali Jumu'ah, al-Madkhal (al-Qahirah: Dār al-Salām, 2004), 8. 
bagi memperkenalkan jati diri atau nature fiqh Islam dan seterusnya menjelaskan dan membuktikan hakikat kesesuaian dan kelestarian fiqh agar sentiasa kekal di atas prinsip dan fikrahnya seperti dahulu dan pada masa yang sama sentiasa diyakini sebagai tempat rujukan dan panduan dalam kehidupan masyarakat.

Selain dari ciri-ciri dan sifat serta jati diri fiqh, fiqh lestari juga menyentuh tentang sumbangan prinsip-prinsip fiqh Islam dalam pelbagai bidang dan aktiviti kehidupan manusia secara praktikal bagi menjamin suasana kehidupan yang lestari, adil dan harmoni.

Fiqh Islam sebagai yang diketahui merupakan satu produk daripada ijtihad para ulama' Islam dalam memahami nas-nas syarak yang luas dan komprehensif. Dengan itu fiqh Islam juga mencakupi keseluruhan bidang hidup yang sangat luas dan komprehensif. Walaupun bukan semua bidang dalam kehidupan manusia dijelaskan secara terperinci dalam sumber-sumber fiqh, namun fiqh Islam tetap memberi sumbangan dalam bentuk penetapan prinsip-prinsip umum bagi memandu dan mengawal dinamika kehidupan manusia yang sentiasa bergerak dan berubah itu agar tidak melencong dari landasan yang sepatutnya.

Fiqh Islam tidak memberikan perincian dan pendetailan secara rigid dalam bidang-bidang dan aktivitiaktiviti hidup manusia yang dinamik dan berubah tersebut. ${ }^{5}$ Ini sesuai dengan nas syarak yang menjadi akar umbi kepada fiqh Islam yang tidak memberikan peruntukan yang terperinci dan tetap dalam bidang-bidang dan aktiviti-aktiviti hidup manusia yang dinamik dan berubah. Jika dilihat umpamanya dalam sektor muamalat yang berbeza seperti ekonomi, politik dan sosial, nas-nas syarak hanya menurunkan dalil-dalil yang bersifat ijmālìyy

5 Lihat umpamanya, 'Abd al-Karīm Zaydān, al-Wajīz (Beirut: Mu'assasah al-Risālah, 1987), 157-158; 'Abd al-Wahhāb Khallāf, Ilm Ușūl al-Fiqh (t.p: Dār al-Qalam, t.t.), 33-34. 
atau menyeluruh sahaja sementara aspek pendetailannya dipulangkan kepada manusia mengikut kesesuaian suasana, masa dan tempat asalkan menetapi falsafah dan prinsip syariat.

Prinsip-prinsip fiqh yang disumbangkan dalam ketiga-tiga sektor utama dalam kehidupan manusia iaitu politik, ekonomi dan sosial sangat menekankan tentang pencapaian matlamat keharmonian hidup manusia yang berkekalan dan merata. Ia menekankan tentang keadilan sejagat, persamaan kemanusiaan, kebebasan yang bertanggungjawab, pemeliharaan alam dan sebagainya. Nilai-nilai ini merupakan asas, landasan dan juga hala tuju dalam pemikiran lestari. Nilai-nilai inilah juga merupakan asas dan hala tuju prinsip-prinsip fiqh Islam dalam kehidupan manusia.

Penekanan kepada nilai-nilai ini dalam semua sektor kehidupan manusia melalui penerapan prinsip-prinsip fiqh Islam inilah juga yang dimaksudkan dengan fiqh Islam lestari iaitu sumbangan prinsip-prinsip fiqh Islam dalam semua sektor kehidupan manusia bagi mencapai kehidupan yang berasaskan keadilan, persamaan, kebebasan dan kedamaian yang lestari, berterusan dan berkekalan.

Secara ringkasnya konsep fiqh lestari yang cuba diketengahkan dalam artikel ini boleh difahami dalam dua dimensi. Pertama ialah kelestarian dari sudut disiplin ilmu fiqh. Ilmu fiqh itu perlulah sentiasa hidup, segar dan lestari sebagai panduan manusia sepanjang zaman dalam menghadapi pelbagai cabaran. Untuk itu, maka ilmu fiqh mestilah berteraskan kepada ciri-ciri tertentu yang boleh memastikan kelestariannya sepanjang masa dan dengan itu tidak dipinggirkan oleh masyarakat. Kedua ialah ilmu fiqh dan pemikiran Islam itu mengandungi banyak prinsip dan perkaedahan yang boleh disumbangkan dalam menwujudkan suasana pembangunan dan kehidupan yang lestari dalam semua bidang hidup manusia sama ada 
politik, ekonomi, sosial, alam sekitar, sains, teknologi dan sebagainya. Prinsip-prinsip inilah yang ingin dikenalpasti dan diketengahkan.

Jadi secara ringkasnya fiqh lestari itu bermaksud, pertama, ciri-ciri kelestarian ilmu fiqh dan pemikiran Islam, dan kedua, prinsip-prinsip pembangunan lestari dalam semua bidang hidup yang boleh ditawarkan oleh ilmu fiqh. Dari segi ciri-ciri kelestarian ilmu fiqh tersebut, terdapat beberapa ciri yang boleh senaraikan yang menjamin kedudukan dan peranan ilmu fiqh dalam masyarakat antaranya seperti fiqh yang berasaskan dalil yang sahih, fiqh yang pasti dan tetap dalam aspek prinsip, fiqh yang anjal dan dinamik dalam aspek furu', fiqh yang mengekalkan kesinambungan manhaj pemikiran fiqh silam, figh yang berasaskan kemudahan yang dibenarkan dan susunan awlāwiyyāt yang betul, fiqh yang mengambilkira maqāṣid, mașālih, dan waqi' masyarakat, fiqh yang tidak taksub kepada pandangan mazhab atau tokoh tertentu dan fiqh yang membantu kearah kemajuan masyarakat secara holistik. ${ }^{6}$

\section{Analisis Isu-Isu Terpilih dalam Hal Ehwal Mu'allaf di Malaysia dari Perspektif Fiqh Lestari}

a. Takrif Mu'allaf

Persoalan tentang takrif mu'allaf bukan sekadar merupakan isu semantik semata-mata tetapi ia turut melibatkan persoalan tentang hukum hakam fiqh. Dengan itu usaha untuk memahami takrif mu'allaf dengan betul sangat penting kerana ia juga akan memastikan kelestarian fiqh khususnya yang berkaitan hukum tentang mu'allaf.

Kata mu'allaf merupakan kata nama maf' $\bar{u} l$, dari kata dasar alla-fa yang bererti menjinakkan dan mu'allaf

\footnotetext{
6 Untuk huraian setiap ciri-ciri berkenaan secara khusus lihat umpamanya, Atikullah Abdullah, "Konsep dan Ciri-Ciri Fiqh Lestari: ke Arah Mengarusperdanakan Fiqh dalam Kehidupan Masyarakat", Jurnal Syariah, bil.3, jil.18 (2010).
} 
bererti yang dijinakkan iaitu segolongan manusia atau individu yang dijinakkan hati mereka untuk memperkuatkan keyakinan mereka kepada Islam atau untuk menerima Islam atau untuk tidak melakukan kejahatan ke atas orang Islam. Ertinya tindakan menjinakkan itu dilakukan oleh orang Islam ke atas orang bukan Islam yang ada harapan menerima Islam atau untuk mengelakkan dari kezalimannya atau yang baru memeluk Islam yang masih lemah imannya atau yang kuat imannya tetapi menjadi subjek pemerhatian dan ikutan orang bukan Islam atau sebagai insentif mempertahankan orang Islam atau sebagainya. ${ }^{7}$

Al-Shawkāni menyatakan bahawa para fuqaha' berbeza pandangan tentang maksud mu'allaf yang layak menerima zakat. Ada yang menyatakan bahawa ia merujuk kepada golongan kafir yang diberikan zakat untuk menarik minatnya kepada Islam dan ada juga yang menyatakan ia merujuk kepada orang Islam yang mempunyai pengikut dari kalangan orang kafir yang boleh dijinakkan hati mereka melalui pemberian zakat kepada ketuanya yang Islam tersebut. ${ }^{8}$ Secara keseluruhannya menurut para ulama', al-mu'allaf ialah sekumpulan atau seseorang yang diharapkan dapat dilembutkan hati mereka untuk menerima Islam atau mengukuhkan keislamannya atau diharapkan dapat dihalang kezalimannya dan kejahatannya keatas orang Islam atau menarik manfaat mereka untuk mempertahankan orang-orang Islam.

Apa yang jelas dari definisi dan perbahasan para ulama' tentang pengertian mu'allaf ini ialah hakikat bahawa definisinya agak luas dan fleksibel dengan berpaksikan kepada dua asas utama iaitu dakwah dan

7 Al-Bījirmī, Hāshiyah al-Bījirmī, jil.4 (Dār al-Fikr, 1995), 368; alQarāḍāwī, Fiqh al-Zakāt, jil.1 (t.p: Mu'assasah al-Risālah, 1996), 594.

${ }^{8}$ Al-Shawkānī, Nayl al-Awțār, jil.4 (Qahirah: al-Bābi al-Halabīyy, t.t.), 461. 
maslahah, khususnya keselamatan. Jika seseorang itu dirasakan boleh menerima Islam atau boleh menjadi seorang Islam yang lebih baik atau boleh mempengaruhi orang lain untuk menerima Islam atau boleh memberikan manfaat dan keselamatan kepada orang Islam maka ia termasuk dalam kategori mu'allaf sama ada ia seorang Islam atau bukan Islam. ${ }^{9}$

Takrif mu'allaf yang merangkumi orang Islam dan bukan Islam ini juga diguna pakai oleh beberapa jabatan atau pusat zakat di negeri-negeri di Malaysia. Jabatan Zakat Negeri Kedah dan Pusat Urus Zakat Pulau Pinang umpamanya, mentakrifkan mu'allaf sebagai orang kafir yang ada harapan masuk Islam dan orang yang baru masuk Islam yang imannya masih lemah. ${ }^{10}$ Bagaimanapun takrif ini agak sempit kerana hanya menetapkan satu kategori dari orang bukan Islam dan satu kategori dari orang Islam. Sedangkan hakikatnya orang Islam yang diberikan zakat atas kapasiti mu'allaf bukan sahaja kerana iman yang masih lemah tetapi juga kerana faktor-faktor yang lain seperti yang disebutkan di atas.

Dalam suasana, masa dan tempat yang berbeza, umat Islam menghadapi cabaran dakwah dan keselamatan yang berbeza. Maka takrifan mu'allaf yang luas dan fleksibel ini memberikan ruang yang mencukupi untuk umat Islam mengaplikasi hukum-hakam Islam yang berkaitan mu'allaf yang selari dengan keperluan dan tuntutan dakwah dan keselamatan yang berbeza-beza dalam masa, tempat dan suasana yang berbeza. Ini menjadikan hukum hakam fiqh Islam dalam hal yang berkaitan dengan mu'allaf ini sentiasa releven, praktikal dan lestari. Takrif mu'allaf yang luas, inklusif dan fleksibel seperti yang telah dibuat oleh para fuqaha' dan mufassir silam ini jelas sekali menampakkan unsur kelestarian yang telah sedia

\footnotetext{
${ }^{9}$ Al-Qarāḍāwī, Fiqh al-Zakāt, jil.2, 595-597.

${ }^{10}$ Lembaga Zakat Negeri Kedah, www.zakatkedah.com dan Zakat Pulau Pinang, www.zakatpenang.com.
} 
wujud dan sebati dalam pembentukan dan perkembagan fiqh Islam sejak dahulu lagi.

b. Pemberian zakat kepada mu'allaf

Dalam membincangkan tentang golongan mu'allafāt qulübuhum yang layak menerima zakat, para mufassir dan fuqaha' membahagikan golongan ini kepada dua golongan iaitu orang Islam dan bukan Islam seperti yang telah dibincangkan di atas. Bagi orang Islam terdapat enam kategori yang termasuk dalam mu'allaf iaitu:

i. Ketua-ketua orang Islam yang mempunyai persahabatan dan menjadi perhatian orang kafir. Jika diberikan zakat kepada golongan ini diharapkan ia memberi kesan kepada keislaman para sahabat, pemerhati dan ahli kaumnya untuk menerima Islam seperti tindakan Abū Bakr memberi zakat kepada 'Adī ibn Hātim dan Zabarqān ibn Badr kerana kedudukan mereka dalam kabilah mereka.

ii. Ketua-ketua orang Islam yang lemah imannya tetapi dihormati dan ditaati oleh kaumnya dan diharapkan jika diberikan zakat kepada golongan ini dapat menguatkan iman di hati mereka seperti tindakan Rasulullah SAW memberikan zakat kepada ketuaketua masyarakat yang baru memeluk Islam selepas peperangan Hunayn.

iii. Individu yang tinggal di perbatasan negara yang menjadi benteng dari serangan musuh.

iv. Individu yang baru memeluk Islam dan masih lemah keimanan dan keislamannya.

v. Individu Islam yang mempunyai kuasa keatas kaumnya bagi memaksa mereka membayar zakat.

vi. Individu Islam yang hidup sentiasa mencari habuan dunia dan dibimbangan dihasut oleh musuh Islam untuk kepentingan mereka. ${ }^{11}$

${ }^{11}$ Al-Nawāwì, Rawḍāt al-Ṭālibīn, jil.2 (Beirut: al-Maktab al-Islamiyy, 1991), 313; Lihat juga al-Qarāḍāwī, Fiqh al-Zakāt, 595-596. 
Bagi orang-orang bukan Islam pula, terdapat dua kategori iaitu:-

i. Individu yang diharapkan keimanannya seperti Sofwan ibn Umayyah yang diberikan harta rampasan perang Hunayn.

ii. Individu yang dibimbangan kejahatan dan kezalimannya maka diberikan zakat kepadanya untuk menghalang kejahatannya ke atas orang Islam seperti zakat yang diberikan oleh Rasulullah SAW kepada Abū Sufyān, 'Uyaynah ibn Hasn dan alAqrā' ibn Habis. ${ }^{12}$

Bagaimanapun Imam al-Shāfi' $\bar{i}$ berpendapat zakat hendaklah diberikan kepada individu Islam sahaja dan tidak boleh diberikan zakat kepada orang kafir walaupun dengan tujuan untuk menjinakkan hatinya kepada Islam kecuali setelah mereka telah memeluk Islam. Imam alShāfi'i menghujahkan harta yang disedekahkan oleh Rasulullah SAW selepas peperangan Hunayn itu merupakan harta al-fay' bukan harta zakat. Jika diandaikan harta yang diberikan oleh Rasulullah SAW itu dari harta zakat sekalipun, namun ada pendapat yang mengatakan bahawa mereka ini telah memeluk Islam sebelum diberikan zakat maka mereka termasuk dalam kategori orang Islam, bukan golongan kuffar. ${ }^{13}$

Pandangan yang lebih ketat ialah yang diberikan oleh Imam Abū Hanifah dan para sahabatnya. Mereka berpendapat bahawa saham golongan mu'allaf telah gugur dan dinasakhkan dengan tersebar luasnya Islam seperti yang telah dilaksanakan oleh khalifah 'Umar al-Khațtāb. Dengan itu tidak lagi boleh diberikan zakat untuk tujuan ta'lif kepada golongan mu'allaf sama ada muslim atau bukan Islam. Dalam pada itu Imam al-Nawāwì dalam kitabnya al-Majmū' ada menyatakan bahawa terdapat

12 Al-Nawāwì, Rawḍāt al-Ṭālibīn, 313; Lihat juga al-Qarāḍāwi, Fiqh al-Zakāt, 595-596. 
tabi'in khususnya Ibn Sirīn dan al-Zuhri berpendapat bahawa harus diberikan zakat kepada kafir zimmiy. ${ }^{14}$ Pandangan ini juga turut dikongsi bersama oleh alQarāḍāwi. ${ }^{15}$

Bagaimanapun terdapat ulama' yang berpendapat bahawa pandangan yang paling tepat dalam hal ini ialah mesti didasarkan kepada keperluan. Jika ada keperluan untuk melembutkan hati golongan kuffar, sama ada untuk tujuan dakwah kepada Islam atau untuk tujuan mengelakkan bahaya dan memperolehi keselamatan, maka zakat boleh diberikan kepada mereka. Hakikat bahawa khalifah 'Umar al-Khaț̣āb dan khalifah selepasnya tidak memberikan zakat kepada golongan ini bukan kerana ia dilarang secara mutlak atau tidak bermakna hukumnya telah dinasakhkan, tetapi kerana tiada keperluan pada masa mereka. Ini bermakna, jika keperluan itu timbul pada bila-bila masa sahaja, maka hukum asalnya akan berjalan semula.

Bagaimanapun yang menentukan sama ada wujud keperluan dan maslahah untuk diberikan zakat kepada golongan yang belum memeluk Islam atas kapasiti mu'allaf itu tidak boleh ditentukan oleh individu pembayar zakat itu sendiri atau mana-mana individu lain sewenang-wenangnya. Penentuan dan keputusannya mestilah dibuat oleh pihak pemerintah khususnya badan yang mempunyai kewibawaan ilmu dan taqwa yang tinggi. ${ }^{16}$ Pandangan ini selaras dengan prinsip fiqh lestari yang bergerak atas prinsip kepatuhan nas dan menjamin dan memastikan kemaslahatan Islam dan masyarakat Islam seluruhnya sepanjang waktu.

Di Malaysia, sepanjang pengetahuan penulis, walaupun definisi mu'allaf yang digunapakai merangkumi

\footnotetext{
${ }^{14}$ Al-Nawāwì, al-Majmū', jil.6 (Dār al-Fikr, 2010), 246.

${ }^{15}$ Al-Qarāḍāwì, Fiqh al-Zakāt, jil.2, 597.

16 Al-Qaradawi, Fiqh al-Zakah, jil.2, (Mu'assasah al-Risalah, Beirut, 1996), 608
} 
orang Islam dan bukan Islam yang ada harapan memeluk Islam, namun sehingga kini belum ada bahagian zakat mu'allaf yang diberikan kepada golongan bukan Islam tersebut. Barangkali hal ini berlaku kerana menurut pandangan yang muktamad dalam mazhab al-Shāfi' $\bar{i}$ sendiri dan juga kerana tiada keperluan dan maslahah untuk langkah tersebut buat masa ini.

c. Tempoh masa sebagai Mu'allaf

Mu'allaf yang baru memeluk Islam berkemungkinan besar menghadapi pelbagai cabaran dan dugaan akibat dari pertukaran agamanya dari agama asal. Ini termasuklah kesukaran dari segi kewangan, hubungan kekeluargaan dan kemasyarakatan dan sebagainya. Selain itu, oleh kerana ia baru memeluk Islam, ia juga menghadapi kesukaran dari segi penghayatan Islam sendiri kerana masih baru baginya. Dalam situasi ini, ia sentiasa terdedah kepada kelunturan iman dan risiko kembali kepada agama asalnya. Kerana itulah antara lainnya disyariatkan memberi zakat kepada mu'allaf dengan tujuan untuk membantu dan menenangkan hati mereka bagi menghadapi cabaran tersebut.

Peruntukan ini juga dapat membantu mereka ke arah proses mempelajari dan mendalami pengetahuan agama dan seterusnya dapat memperkukuhkan keimanannya kepada agama barunya. Oleh kerana itu, maka tempoh status sebagai mu'allaf itu hendakla berdasarkan kepada masa yang perlu diambil bagi menenangkan hatinya, melengkapkannya dengan ilmu pengetahuan syariat yang munasabah dan seterusnya memperkukuhkan imannya.

Realitinya, setiap individu mu'allaf menghadapi jenis dan kadar cabaran dan dugaan yang berbeza dan mereka juga memilki keupyaan yang berbeza untuk menghadapi cabaran tersebut. Selain itu tempoh untuk mereka mempelajari ilmu agama dan memahaminya juga barangkali berbeza antara satu individu dengan yang lain. Begitu juga tempoh untuk menenangkan hati mereka dan 
memperkukuhkan iman juga berbeza. Dengan itu tempoh masa bagi meletakkan status mereka sebagai mu'allaf juga hendaklah berbeza-beza.

Sekadar kajian penulis secara ringkas ini, belum ditemui kadar tempoh tertentu yang diletakkan oleh nasnas mahupun dalam perbendaharaan fiqh Islam mengikut perbezaan bagi perkara-perkara yang dinyatakan di atas. Namun dihujahkan bahawa tempoh status muallaf ini hendaklah diberikan berdasarkan perbezaan keupayaan setiap individu dalam menghadapi cabaran-cabaran dan keperluan kemantapan ilmu dan iman seperti yang dinyatakan di atas.

Di Malaysia tempoh status mu'allaf berbeza-beza antara negeri-negeri. Umpamanya Selangor memperuntukkan tempoh selama tiga tahun selepas pemelukan Islam, Kedah dua tahun, Johor lima tahun, Pulau Pinang tidak dinyatakan tempoh dan sebagainya. Walaupun penetapan tempoh-tempoh ini ada kewajarannya dari segi pentadbiran, kewangan dan moralnya, namun dalam perlaksanaannya perlulah melihat secara praktikal kepada setiap kes berdasarkan realiti dan meritnya. Perlaksanaan yang terlalu rigid dan ketat terhadap penetapan tempoh masa ini mungkin dalam beberapa keadaan tidak membantu ke arah matlamat menjinakkan hati dan menyebarkan dakwah dan dengan itu membantutkan kelestarian fiqh dan kesesuainnya dengan keperluan masyarakat semasa.

Walaupun secara umumnya peraturan dasar dalam hal ini perlu untuk dijadikan garis panduan umum, namun pada peringkat perlaksanannya ia perlulah mempunyai sedikit ruang fleksibiliti bagi pencapaian matlamat syariat secara lestari. Perlaksanaan tempoh mu'allaf mengikut kerluan setiap individu mu'allaf ini amat menepati konsep fiqh lestari khususnya keperluan memenuhi ciri keanjalan dan dinamik dalam aspek furu' serta ciri maslahah, maqasid dan realiti masyarakat. 
d. Pendekatan dakwah dan bimbingan kepada mu'allaf Mu'allaf dalam definisinya yang umum meliputi golongan yang telah memeluk Islam dan belum memeluk Islam. Dari definisi umum tersebut jelas bahawa mu'allaf merupakan individu atau golongan yang terlalu baru atau belum pernah mengenali Islam. Maka menjadi tugas para pendakwah dan pihak-pihak yang berkenaan untuk menyampaikan mesej dakwah Islam kepada mereka. Bagaimana mereka melihat, menilai dan menghayati Islam pada peringkat awal ini banyak bergantung kepada apa yang disampaikan kepada mereka oleh pihak-pihak yang berkenaan dalam tempoh tersebut.

Untuk memudahkan kefahaman dan penghayatan mereka terhadap perkara-perkara asas yang terdiri daripada rukun dan wajib dalam perlaksanaan Islam maka para pendakwah dan guru perlulah menyampaikan dakwah dan ilmu mengikut keutamaan yang betul. Baik dalam pegangan akidah, amalan syariah maupun penghayatan akhlak, perkara-perkara yang menjadi pokok dan asas hendaklah diutamakan dari perkara-perkara yang merupakan cabang dan tambahan, perkara-perkara yang muttafaqh `alayh hendaklah didahulukan daripada perkara yang mukhtalaf fih, wajib didahulukan dari pada sunat, fard 'ayn sebelum fard kifāyah dan haram sebelum makruh. Dalam bidang akidah, contohnya, tidak perlulah menimbulkan kekeliruan kepada para mu'allaf ini tentang perbezaan metodologi dan kefahaman antara salafi dan khalafi, Asyā irah dan Mu'tazilah dan sebagainya.

Begitu juga dalam penghayatan syariat, tidak perlulah membincangkan tentang khilaf antara pelbagai mazhab fiqh dalam sesuatu hukum. Begitu juga dalam bidang penghayatan akhlak, apa yang perlu disampaikan ialah keperluan seseorang yang telah memeluk Islam untuk berakhlak dengan akhlak-akhlak yang terpuji bukan membincangkan sama ada menyertai tarikat itu perlu atau tidak dan sebagainya. Pemilihan bahan pengajaran dan 
dakwah mengikut keutamaan sesuai dengan keadaan subjek yang diajari dan didakwahkan ini akan memastikan kelestarian fiqh al-da'wah dan fiqh al-ta'lim yang tepat dan berkesan.

e. Hubungan dengan mu'allaf

Dalam konteks hubungan dengan mu'allaf, tidak timbul apa-apa isu penting antara sesama Islam sama ada yang telah lama Islamnya atau masih baru Islamnya yang dikenali sebagai mu'allaf. Hubungan mereka adalah sekurang-kurangnya hubungan saudara seagama atau lebih dari itu jika ada pertalian lain seperti darah daging, perkahwinan, kejiranan dan sebagainya. Isu tentang hubungan dengan mu'allaf ini mungkin timbul apabila takrif mu'allaf yang luas seperti yang diberikan sebahagian ulama' dan yang diterima pakai oleh negerinegeri di Malaysia iaitu yang merangkumi orang bukan Islam yang ada harapan untuk menerima Islam.

Asas utama yang menggariskan bentuk hubungan antara orang Islam dengan bukan Islam ialah firman Allah dalam surah al-Mumtahinah ayat 8 yang bermaksud: "Allah tidak melarang kamu dari berbuat baik dan berlaku adil keatas orang yang tidak memerangi kamu dalam agama dan tidak menghalau kamu keluar dari tanah air kamu". Walaupun terdapat mufassirin yang berpendapat bahawa ayat ini telah dimansukhkan oleh ayat al-sayf ${ }^{17}$ yang turun selepasnya, namun menurut Ibn Jarï seperti yang dinakalkan oleh Ibn Muflih dan dipetik pula oleh 'Ali Jumu'ah, sebahagian besar mufassirin dan ulama' lain menolak dakwaan nasakh ini atas alasan antara lainnya amalan yang ditunjukkan oleh Rasullah SAW sendiri tidak memberi petunjuk kepada nasakh ayat ini. Baginda menunjukkan sikap yang baik dalam hubungannya dengan

17 فاقتلوا المشركين حيث وجدتموهم : al-Tawbah: 5. 
golongan bukan Islam termasuk musyrikin Mekah yang memusuhinya. ${ }^{18}$

Usaha menta'lif atau menjinakkan hati orang bukan Islam kepada Islam mesti dilakukan melalui pemeliharaan hubungan yang baik antara orang Islam dengan bukan Islam. Hubungan baik dengan orang bukan Islam menjadi lebih mustahak lagi untuk dipelihara jika mempunyai pertalian kekeluargaan. Rasulullah SAW sendiri bukan sahaja membenarkan Asma' berbuat baik kepada ibunya yang musyrik, malah baginda memerintahkan Asma' untuk sentiasa menjaga hubungan silaturrahim dengan ibunya tersebut. ${ }^{19}$ Bagi mengesahkan tindakan ini maka Allah SWT menurunkan ayat 8 surah al-Mumtahinah yang telah lalu. Al-Bukhārī juga meriwayatkan bagaimana Sayyidina 'Umar masih memelihara hubungan kekeluargaanya dengan adiknya yang masih musyrik di Mekah dengan mengirimkan kepadanya pakaian yang bermutu tinggi yang diperolehinya.

Selain dari hubungan kekeluargaan, sirah Rasulullah SAW dan sejarah generasi Islam awalan juga banyak mencatatkan peristiwa bagaimana kebaikan yang banyak dilakukan oleh orang Islam kepada bukan Islam. Rasulullah SAW sendiri diriwayatkan saling memberi dan menerima hadiah dari pembesar bukan Islam dari negaranegara luar dan baginda menziarahi golongan bukan Islam termasuklah orang Yahudi. Sikap yang baik kepada bukan Islam ini diikuti oleh para sahabat selepasnya. 'Umar alKhațāāb sering memberi sedekah kepada golongan miskin dan memerlukan termasuk kepada orang Yahudi yang meminta sedekah daripadanya. ${ }^{20}$

Kerana itu para ulama' hampir sepakat mengatakan Islam sama sekali tidak menghalang pemeliharaan

\footnotetext{
18 'Alī Jumu'ah, al-Bayān (Qahirah: al-Muqattam, 2005), 57-58.

19 Al-Bukhārí, al-Jāmi' al-Ṣah̄ihh, Bab hadiyyah li al-mushrikīn, no. 2426; Muslim, al-Jāmi' al-Ṣahịh, no.1671.

20 'Alï Jumu'ah, al-Bayān, 57.
} 
hubungan yang baik antara orang Islam dengan bukan Islam, sama ada yang ada harapan untuk menerima Islam atau yang tiada harapan, apatah lagi jika mereka mempunyai hubungan kekeluargaan atau kejiranan selama kebaikan yang dilakukan itu tidak memberi makna membesar dan meredai kekufuran mereka.

Al-Sarakhsi menyatakan seperti yang dinakalkan oleh 'Ali Jumu'ah: "silaturrahim merupakan sesuatu yang baik dan terpuji dalam semua agama dan amalan memberi hadiah merupakan sebahagian dari kemuliaan akhlak dan Rasulullah SAW bersabda yang bermaksud, "aku diutuskan untuk menyempurnakan kemuliaan akhlak". Maka kita dapat fahami bahawa sikap tersebut merupakan sesuatu yang baik sama ada bagi orang Islam ataupun musyrikin". ${ }^{21}$

Lebih dari itu, para ulama' juga berpendapat bahawa adalah diharuskan untuk umat Islam berdoa bagi orang bukan Islam supaya diberikan hidayah dan kesihatan tubuh badan oleh Allah SWT. Selanjutnya Imam alNawāwi menakalkan hadith yang diriwayatkan oleh Ibn Sunni yang menceritakan tentang doa Rasulullah SAW kepada seorang Yahudi yang memberi minum kepada baginda agar beliau sentiasa kelihatan tampan, dan doa ini dikatakan dimakbulkan Allah. ${ }^{22}$

Apa yang dibincangkan ini melambangkan kefahaman (fiqh) dan pendekatan yang lestari dan berkesan dalam menyusun bentuk hubungan dengan orang bukan Islam sebagai satu usaha dakwah ke arah menta'lif dan menjinakkan hati mereka bagi menerima Islam. Kefahaman dan pendekatan ini bertepatan dengan prinsipprinsip fiqh lestari yang berdiri di atas petunjuk-petunjuk nas yang sahih dan jelas selain menepati kehendak dan

${ }^{21}$ Ibid.

${ }^{22}$ Al-Nawāwī, al-Azkār (Al-Qāhirah: Dār al-Rayyān li al-Turāth, t.t), 317. 
realiti semasa serta maslahah dan kepentingan masyarakat Islam seluruhnya.

\section{Kesimpulan}

Pemikiran fiqh Islam hendaklah dibina dan dikembangkan di atas ciri-ciri dan prinsip-prinsip yang menjamin kelestariannya sepanjang zaman supaya ia mampu terus kekal menjadi landasan rujukan utama masyarakat Islam dan mampu pula secara berterusan dan lestari memberikan sumbangan kepada masyarakat seperti yang telah ditunjukkan oleh generasi Islam awalan. Pemikiran fiqh lestari mampu diterjemahkan dalam pelbagai bidang hidup umat Islam termasuklah dalam bidang yang mengatur hukum hakam tentang mu'allaf. Penerimaan dan pemakaian pemikiran fiqh lestari dalam bidang yang berkaitan dengan mu'allaf bukan sahaja akan menjamin kebaikan dan kemaslahatan mu'allaf tetapi juga masyarakat Islam seluruhnya dan lebih penting lagi membantu kearah penerimaan dan penyebaran Islam yang lebih meluas.

\section{Rujukan}

'Abd al-Wahhāb Khallāf. 'Ilm Ușūl al-Fiqh. t.t: Dar alQalam, t.t.

Alì Jumu'ah. Al-Bayān limā Yushghil al-Azhān. AlQāhirah: al-Muqattam, 2005.

Alī Jumu'ah. Al-Madkhal ilā Dirāsāt al-Madhāhib alFiqhiyyah. Al-Qāhirah: Dār al-Salām, 2004.

Atikullah Abdullah, "Konsep dan Ciri-Ciri Fiqh Lestari:

Ke Arah Mengarusperdanakan Fiqh dalam Kehidupan Masyarakat", Jurnal Syariah, bil.3, jil.18 (2010).

Al-Bījirmi, Sulaymān ibn Muhammad ibn 'Umar. Hāshiyah al-Bījirmī, jil.4. Dimasyq: Dār al-Fikr, 1995.

Kamus Dewan, Edisi Keempat. Kuala Lumpur: Dewan Bahasa dan Pustaka, 2005.

Musțafā al-Khīn et.al. Al-Fiqh al-Manhajīyy 'alā Mazhab al-Imām al-Shāfi ‘ìyy. Dimasyq: Dār al-Qalam, 2003. 
Al-Nawāwī, Yahya ibn Sharaf. Al-Azkār. Al-Qahirah: Dar al-Rayyan li al-Turath, t.t

Al-Nawāwì, Yahya ibn Sharaf. Rawḍāt al-Țālibìn, jil.2, Beirut: al-Maktab al-Islamiyy, 1991.

Al-Nawāwī, Yahyya ibn Sharaf. Al-Majmū', jil.6. Beirut: Dar al-Fikr, 2010

Al-Shawkāni. Nayl al-Awtār, jil.4. Qahirah: al-Babi alHalabiyy, t.t.

Lembaga Zakat Negeri Kedah, www.zakatkedah.com

Zakat Pulau Pinang, www.zakatpenang.com.

Al-Qarāọāwī, Yūsuf. Bay' al-Murābahah li al-Amir bi alShirā'. Al-Qāhirah: Maktabah Wahbah, 1995.

Al-Qarāḍāwí, Yūsuf. Fiqh al-Zakah, jil.2. Beirut: Mu'assasah al-Risalah, 1996

Zaydān, 'Abd al-Karīm. Al-Wajīz. Beirut: Mu'assasah alRisālah, 1987.

Zaydān, 'Abd al-Karīm. Al-Madkhal li Dirāsāt alSharì'ah al-Islāmiyyah. Beirut: Mu'assasah al-Risālah, 1986.

Al-Zuhayli, Wahbah. Al-Fiqh al-Islāmīyy wa Adillatuh. Dimasyq: Dār al-Fikr, 1989. 